(Bulletin de Therapeutique, tome xnI, p. 41.) And in the recent edition of the elaborate treatise of $M$ M. Barthez et Rilliet, the topical treatment of hooping-cough obtains a place amongst the available remedies for the disease. I shall be excused for quoting their brief but sufficient description of the method:- "Le Docteur Watson a conseillé l'emploi de la cautérisation pharyngo-laryngée arec une solution de nitrate d'argent de 75 centigrammes aे 2 grammes 40 centigrammes pour $30 \mathrm{gr}$. d'eau distillée. M. Watson se sert d'une éponge solidement fixée à une baleine accourbée; la tête du malade étant fixée par une aide, et la langue prealablement abaissée, il porte l'éponge jusqu'à l'ouverture de la glotte; il résulte de cette petite opération une sensation de suffocation très légère et temporaire que l'enfant a bientot oublié." (Traité Clinique et Pratique des Maladies des Einfants, 2me edition, tom. II, p. 657, published in 1853.)

I hope, then, that it may not be utopian to expect that the day is not distant when the treatment, so well described by these excellent writers, and the usefulness of which I have now been enabled to establish, very mainly, through the generous zeal and untiring perseverance of another French physician, will be more favourably received in this country, and more generally adopted by British practitioners of medicine. Were such to be the case, I do not doubt that the result would be displayed in a marked diminution of mortality among children, and in the removal of a longstanding opprobrium to the healing art.

Glasgor, August 18:3.

\section{ON CHOLERA, AND ITS TREATMENT BY} COLD WATER AFFUSION OR DOUCHE.

By E. M. MAClIIERSON, Esq., late Surgeon in the Army.

Having had various opportunities of treating cholera, during a service of nine years in India, and of testing the efficacy of cold water affusion in many cases of the worst description, since June 1845, I belicve that a report upon this mode of treatment, which has been found so immediate in its effects, and beneficial in its results, will merit attention. And, if conclusions may be drawn from the ostensible principle of its action, the real nature of cholera cannot fail to be more distinctly recognised than has yet been acknowledged.

Beforc entering upon this report, it may be advisable, for the elucidation of the subject, to glance at the difference supposed to exist between cholera in Europe and cholera in Asia; and, for the better appreciation of the treatment proposed, to determine, from the copious and accurate data rccorded of cholera, what is the leading characteristic of the disease, and what ought to be the object of our treatment in regard to it.

That the difference supposed to exist between the Asiatic and European forms of cholera is one of degrec only, not of kind, will be evident on a cursory inquiry. IIence it will also be evident that the treatment applicable in the one form, is equally so in the other. In Asia, where the disease may be said to be indigenous, cholera, true to its history, bursts forth in all its vigour, and from the first appears in its advanced stage, or stage of collanse-in this country denominated its second stage. But when, after its onset in this advanced stage, it subsides in the virulence of its attacks, and the cases become milder, more amenable to treatment, and less rapidly fatal, it will be found to assume that form of the disease in which vomiting, purging, and cramps, prevail, and to be in every respect identical with the so-called European cholera.

In Europe, on the other hand, where the disease is almost invariably ushered in by vomiting, purging, and cramps, these symptoms constitute its first stage; but when these symptoms have ceased, and when, as dissolution approaches, the first has passed into the second stage, or stage of collapse, cholera in Europe will be found identical with cholera in Asia, whcre so many are struck down almost lifeless from the first.
How far these symptoms, vis. the romiting, purging, and cramps (upon which so much stress has been laid in the pathology and treatment of the disease), ought to be taken into account, the known history of cholers in all places, and under all circumstances in which it has shown itself, will satisfactorily decide.

If the value of a symptom, with a view to treatment, is. to be regarded in proportion to its influence on the fatality of a disease, then neither the vomiting, nor purging, nar cramps, will be found worthy of any consideration whatever in the treatment of cholera.

In the words of Dr. Copland, in his treatise on cholera: "The vomiting and purging, which are far from being the most dangerous symptoms, and are often the most remarkable in the least urgent cases, are generally slight, or at least not profuse, in those attacks where the sinking of the vital energies is the most rapid and greatest, and are readily allayed by medicines. The spasms are often slight, or nearly absent, in some of the most rapidly fatal cases."

That these remarks are fully borne out by the history of the disease, all who enter into the subject, and extend their observations beyond their own doors, may satisfy themselves.

They may also infer, what must be obvious to most who have had experience of cholera in India, that the symptoms in question, - the vomiting, purging, and cramps,-if at all constant in their relation to the disease, seem to be so in an inverse ratio, as in compression of the brain, to the depression of vital energy. In other words, the collapse or asphyxia, which, with its sequelx, oppressed respiration, impeded circulation, coldness, blueness, etc., is the only invariable symptom, and therefore the leading characteristic of cholera, and ought to be the object of our treatment; not only because it is the only constant symptom, but also, perhaps rather, on the proof which experience will give all who have treated cholera, that reaction is the forerunner of every amelioration in the symptoms during an attack, and the only sign to be depended upon in forming a prognosis. It was in producing this reaction that the cold water effusion or douche was found so beneficial.

At Cawnpore, in June 1845, cholera broke out in the 53rd regiment, to which $I$ then belonged, with the same virulence as attended it in various localities throughout India during that and the succeeding year. Two men, the last survivors of several who had been attacked within two days, were sinking under that fatal collapse which alone, without any other symptoms, marked all the cases that had occurred in the regiment.

Every remedy that could be devised to produce reaction had been tried in vain; they might as well have been put into the patients' breeches pockets, or applied to the bedpost. The exhibition of the nitrous oxide gas was not only fruitless, but far from encouraging. The breathing under its use became more oppressed and hurricd; there was no pulse, nor was it rendered perceptible by the gas; and, as its continued exhibition distressed the patient, it was thrown aside as worse than uscless. In despair at the utter want of the most trivial effect from the remedies employed, I made trial of the cold water affusion. I desired the water-carrier to pour water from his leathern bag over one of the patients; and, as the effect was good, then over the other patient, placed naked on a bedstead in the verandah. Attendants were at the same time employed in rubbing the limbs and trunk with their palms, and afterwards with dry towels. A refreshing sensation and comparative reanimation having followed each repetition of this operation, it was had recourse to at intervals, though only with the success of having prolonged life, which was ebbing fast for some hours.

This success, poor though it was, seemed to warrant the conclusion that, had the remedy been applied while somewhat more of life remained, recovery might have been the result. To test this conclusion by experiment, an opportunity was not long wanting.

On the same evening, as if by some fatal blast sweeping over the barracks, several men were suddenly struck down in a state of collapse. Some retained consciousness (cholera 
aphyeria): a fer lost it, and were in a state of complete coma (apoplexia), with stertorous breathing; in three cases, attended with convulsions; others, especially towards morning, and during the two following days, were affected by romiting, cramps, purging with rico-water dejection, and the usual concomitants of cholera in Europe.

How many came under treatment at this time, I cannot now venture to affirm; but $I$ believe $I$ am correct in stating that, of all admitted, but two died-one of apoplexy; the other, who was allowed a warm bath, of cholera. The rest, all of whum recovered from the cholera, were treated by the cold water affusion.

Since the period above alluded to, I have not had an opportunity of treating cases of epidemic cholcra. Several cases, however, of endemic cholera among Europeans, while it was, as often happens, epidemic among the uatives, have been treated by me in every instance with success.

One of the most remarkable of these endemic cases occurred at Meerut, in August 1848. A corporal of the 9th Lancers, an atrabilious subject, was brought to hospital at 4 P.M., almost pulseless, having been purged during the morning, and having passed several rice-water dejections on adinission into hospital. There were slight cramps, and occasional efforts to vomit. He was immediately placed in a hip-bath, and water was poured over him, while hospital attendants rubbed the limbs and trunk. This was continued until he became chilly, and shivered. IIe was then removed from the bath, dry rubbed, and placed in bed, much revived by the operation, as was shown by less oppression in breathing, and a more distinct pulse. After remaining in bed for about half an hour, he began to relapse; the pulse sank; vomiting, purging of rice water, and cramps, returned. He was replaced in the bath, with the same effect as before. Being again placed in bed, he again relapsed. The water was again had recourse to, and repeated at intervals as above, according to symptoms, until 10 P.M., six hours after its first application. The respiration then became free, the pulse soft and distinct; the natural warmth was restored, and remained; and the patient slept until morning, when he awoke with a furred tongue, feeling weak and drowsy, but without that consecutive fever so often more fatal than the disease itself, and which has always seemed to me to follow most in those cases in which brandy, opium, ammonia, or other stimulants, have been freely administered.

Meagre and unsatisfactory as the above statements must appcar, taken as evidence of the efficacy of the treatment advocated, yet, if the action of the remedy shall be thought to afford a satisfactory explanation of its curative effect, one case successfully treated in the manuer prescribed will carry more weight than accurate details of numerous cases, treated by the unknown action of some occult remedy.

The first effect of cold water, poured over the head and chest in a small stream from a water ewer, held at a greater or less height by a person standing on a chair or raising his arm over the patient placed in a barh while frictions are applied to the trunk and limbs, is to produce, as in cases of ordinary asphyxia, a convulsive gasp or forced inspiration, succeeded by two or three strokes of quickened respiration. With each gasp, as by a convulsive throe, the parietes of the thorax, before immoveable, will be observed to expand, and the diaphragm will descend. Simultaneously with each effort of inspiration, the impeded circulation will be found to flow, the pulse to partake of the impulse, and the sluggish pupil to resume its wonted sensibility. These are the first and immediate effects of the water douche. When continued, they constitute reaction; and if this is maintained, the vital energy, even at its last ebb, the natural heat of the surface, and the colour of the skin will be restored. This is effected by the imbibition into the blood, through respiration, of atmospheric air taken in at cach forced inspiration; the entire surface being at the same time stimulated by frictions to the limbs. It being evident, according to this view, that the stimulating effect of the cold water douche is to be attributed to its power of exciting the respiratory function to take oxygen into the system, it may be inquired how the experiment with the nitrous oxide gas above alluded to failed so signally. One essential condition to its action was wanting; viz., that expansion of the thorax for the reception of air into the lungs, upon which the effect of the water douche so much depends. Since I have become aware of this as an essential condition in the effect produced by the water douche, I have not had an opportunity of repeating it in conjunction with the gas; but may it not be presumed that, taken together, if they do not prove an antidote to the disease, they are at least worthy of a trial. That the want of oxygen in the blood is the cause of cholera, has often been advanced, if not generally admitted; but the effect of this want upon the brain in producing vital depression seems to have been overlooked; while its effect, or that of some poisonous miasm in the system, upon almost every other organ of the body, has been fully insisted upon as indicative of some particular line of treatment to be pursued.

How symptoms are to be regarded as indicative of treatment has already been noticed. Is it not, however, a general law of the system that any violent shock inflicted upon it as in concussion, compression, some cases of poisoning, and in cholera itself, is followed by vomiting, purging, cramps, and suppression of urine, in a greater or less degree according to the nature of the shock, unless vitality shall have been so overwhelmed by the force of the injury as to pass away without any attendant symptoms, save suppression of urine, which being in proportion to the collapse, gives, by its cessation, one of the surest indications that a generous reaction has set in?

In cholera, as in cases of drowning or poisoning by carbonic acid gas, in all of which the post mortem appearances are so strikingly similar, may not suspended animation, collapse, or asphyxia, be ascribed to the paralysing effects of carbonized blood upon the brain? For, precisely in proportion to the removal of this effect by the stimulating agency of oxygen imbibed through the respiration, will reaction ensuc, and the powers of life return, and all the symptoms that characterised the affection disappear. The mode of using the cold water affusion has been pointed out in the case detailed as having been under its operation for six hours. The most essential requisite for the successful application of this mode of treatment was found to be undaunted perseverance, so long as after each relapse reaction could be induced by its repetition. It was a want of a knowledge of the good effect of this perseverance, that caused those two cases first mentioned to be given up in despair. Fach time that the douche was resorted to, its effect was of longer duration; until at length, by watching and perseverance, the respiration, "the pendulum of life", was set in motion; every part of the vital machine dependent upon it moved in concert, and the brain, the mainspring of life, was restored to its wonted power of maintaining the just equilibrium.

With respect to the state of the atmosphere during the time that cholera prevails, much has been said. One simple fact, familiar to many, I would mention, as I have not seen it alluded to before; the dimness of lights, and the dulness of fires in cholera seasons, are as striking as their brightness and briskness in this country in frosty weather. If the presence of oxygen is allowed to be the cause of the latter, the former may be imputed to its absence; and the opposite states of feeling in all animated nature, induced upon those who have experienced both, is beyond question.

The mode of applying the cold water douche merely consists in placing the patient in any convenient position, so that, while water is being pourcd over him, frictions may be applied to the limbs. After the gasping has ceased, this process is to be continued until the depressing effect of cold, shivering, and chattering, sets in, when the pulse will begin to fall. The patient is then to be placed in bed, having been well rubbed. In a short time, when warmth begins to return, relapse will take place. The water is to be repeated in the same manner as above, and persevered in so often as collapse recurs. After each repetition, its effect will be found to be more palpable and more pro- 
longed; until at length, through the agency of the imbibed oxygen, the system is restored to its wonted powrer.

Many hare mentioned in a general way the good effect of cold water in cholera ; but none, I think, have understood the reason of this good effect, and therefore it has not been carried to its full extent.

It may be well to add, for the satisfaction of those who cling to the idea that cholera is a disease of vomiting, purging, and cramps, that under the water treatment, as described, these symptoms will soon cease to be objects of attention. They will in general subside on the first application, and seldom reappear after the third or fourth.

As to internal remedies, water to drink freely will be found the most agreenble to the patient's taste, less productive of nausea and depression, and not so prone to give rise to the often fatal consecutive fever.

As to the premonitory diarrhoa, on which much stress is laid, I would remark that in the worst cases of cholera it neither precedes nor accompanics the disease; that often, where it subsides, cholera sets in ; that where it continues, cholera does not necessarily follow; that it is not part and parcel of the disease; that to view it as such, and to treat it accordingly, can only be in accordance with that style of medical reasoning which has ever puzzled the profoundest lawyers.

Ausunt 1s:3.?.

\section{PERISCOPIC REVIEW.}

\section{SURGERY}

\section{CASES OF CHRONIC IXFLAMIITION OF 'THF} KNEF.,IOIN'T

The fillowing cases are reported in the Lancet for June 4 th and llth.

(AsF. T. Thomas T., aged st years, a serofulous looking chilı, was arlmittel into Isiales wari, in St. Thomas's Hospital, uniler Mr: South, on September 2 :ird, lN51. The patient had becn ailing from infancr, and was attarked ahout three vears previons to getmision with severe pain in the knee joint. 'This ante intlammation subsided after a little while; a twelvemonth passed with comparative ease, when the pain returned, and the child entered (iuy's Hospitul, where he remained fifteen weeks, and then repaired to St. 'Thomas's. On examination, the lines was considerubly swollen, the pain not very severe, but the boy complained when pressure was made on the patella. Theri was much swelling and fluctuation ahove the inner condyle, mol between the ham-string muscles, and also on both sides of the head of the tibia. The leg conll, he moved without assintance or pain, and the ehild did not recollect having struck the knee, or rereived a blow unon it.

Fimollient applicutions and rest were ordered. The swellinir gradually increised for the next three week:; and in alont six, the matter came to the surfare, and pointerl. An oprening was made in a bulging part below the knce, and about four ounces of thin whey-like matter were racuated. The bov's health kept up pretty well, but the di-charge weatened lim. live months after ulmission, fiur sinnses had formed arnund, alove, and below the knee; they all di-charged thick purulent matter, of laudable colour and consistence. 'The ends of the bone seemed romewhat enlarged, the leg was Hexed on the thigh, and the hoy's health was declining, although he had heen kept on nutritiuns diet.

Five montlss after allmission, amputation was performed, whilst the patient was under the influence of chlornform. Very little blood was lost, but the boy vomited several times during the operation. 'There were found thickening of the svovial memliasue, alisorption of cartilages, and caries of hone.

CAs: 11. A. B., aged 15 years, a strumous girl, but in tolerable gencral health, stated that her left knee had been in a morbid conclition for twelve years. Enlargement and intlammation of the joint were supposed to follow an injury with which the patient met when only three years oll. Rest and the usual mode of treatment enabled her after some time to movo about on crutches: but she remained liable to at tacks of inflummation, which nceessitated rest and confinement to bed.

It was after a fall, and a consequent injury to the joint, that
Mr. Brarser first saw this petiont in Guy's Hespital in the summer of 1852: the joint was then almost fixed, but allowed slight flexion, which gave great pain; the patelle was immovable, and the tibia drawn backwards on the femur. After the patient had been kept at rest for about two months, the inflam. matory action subsided, but again commenced as soon as movement of the joint was permitted.

The girl now became quite worn out, and wearied by the idea of confinement to the horizontal posture. At her earnest entreaty, the liml was amputated on 21 st September $1 \times ; i$ :

On examination of the joint, the cartilages could no longer be seen; isolated points of intlammation, with a little pus here and there, were olserved; and some vancular fringe-like filirous formations were in contact with the bones, which werc soft and spongy, and contained much adipose matter.

CaSE 11. William 13., aged 14 years, was admitted into St. Bartholomew's Iospital, September 14 th, 185\%, under the care of Mr. Stavify. He had been employed at saw-mills, had generally enjoyct goml health, and stated that, while working one dar, a bov darte: a piece of pointed wood at him, which entered the fle-h at the knee. He withdrew it; the wonnd hed very little, but the pain was so great that he was obliged to leave his work and go home (about tive minutes' walk). Hi. mother bathed the part with wurm water and applied a ponltice. This treatment was continued for ten days, but the swelling increasing, the patient was brought to the hospital.

On examination, Mr. Wormald considered that fluid was effised in the joint, and he made an incision over the articulation, but not into it. l'urgatives and a sjirit lotion were ordered. 'The swelling at tirst diminisher, but it increased in a few days, ancl pain towirts the imuer part of the thirh was complained of. The leg whs now put into a splint box, small doses of mercury were prescribed, and twelve leerhes applied to the joint. As no improvement tonk place, the leeches were repented. 'Two days after this, an inilurited and puinful spot was noticed on the thigh. Teeches relieved the puin, but the boy was becoming emaciated, and signs of hectic ferer appeared.

One month after admission, an opering nccurred spontanenusly on the external part of the lnce; much pus escaped, and pressure on various parts of the joint caused purulent matter and liood to escape.

Mr. Stanley, on taking charge of the case, enlarged the opening into the articulation, and gave cxit to a great deal of pus mixed with blood. No change of importance occurred for the next few days, except that the whole texture of the thigh assumed a louruy feel, and fluctuation was detected on its inner ide. In exploratory incision was made both on the inner and outer aspect of the thigh. Serum mixed with blood was evacuated, and the prohe, passed into the wound, struck upon bone. Mr. Stanley removed the thigh high up by the flap operation, the patient being under the influence of chloroform. There was destruction of the -ynovial membrane and curtilage, abundunt purulent serretion, principally from the denuded bones, and infiltration of pus in the tissues surrounding the joint.

The bov proressed extremely well for the first eleven days, wh'n he fill into an apathetic state, after being very restless. 'Th' next day, severe pain in the left side of the chest was complainer of, accompanied ly rigors. A pericardial friction sound wits henril over the apex of the heart, lout at no other part of the organ: anil a plemitic rubling sound was detected, after each inspiration, below the left axillu. On the right side the brenthing was coarse and loud, but no morbid sounds were malle out. Delinium was the chief sign for the next few days, with some abatement of the pain. A consultation being held with J). lioupell, sedatives and stimulatin expectorants were ordered; lint the patient fell into a state of coma, the wound censed discharging, and he died on the 4th of November, sixtern davs after the operation.

Framivatiox of the Buny. The left pleura was full of thin puriform fluid, which flowed ont when the thorax was opened. The lung was covered hy a thick laver of rather firm lymph, extending over the whole surface, and also partially between the lobes. The organ. itself was considerably compressed, felt consolidated, and much heavier than natural. The interior of the lung was full of purif $r m$ deposit, consisting in every lobe of circumscribed masses of snft lymph, which yielded pus on pressure. Towards the inferior margin, the pulmonary substance was seen through the pleura to be of yellow colour; and on cutting into this part pus flowed out, the tissue itself being soft, easily broken down by the finger, and appearing as if it had suppurated. The lung and pleura were normal on the right side, save two circumscribed deposits of lymph at the 